\title{
"Marcha nocturna", un poema de Gabriela Mistral publicado en La Nación de Buenos Aires (1942)
}

\author{
"Marcha nocturna": a poem by Gabriela Mistral \\ published by La Nación in Buenos Aires (1942) ${ }^{1}$
}

\author{
YENNY ARIZ CASTILLO \\ ${ }^{a}$ Universidad Católica de la Santísima Concepción. \\ Correo electrónico: yariz@ucsc.cl
}

\begin{abstract}
Análisis de manuscritos y edición del poema "Marcha nocturna" de Gabriela Mistral, a partir del concepto de "unidades de redacción", propuesto por Jean Bellemin Nöel en el marco de la crítica genética. Se comprueba una relación entre la estructura original del poema en cuartetos construidos con binarismos y el llamado a la unión latinoamericana, representado en la amistad de José de San Martín y Bernardo O'Higgins. Asimismo, se indaga en los epistolarios de Mistral con Eduardo Mallea, director del suplemento "Artes y Letras" de La Nación de Buenos Aires, en el que se publicó "Marcha Nocturna”, y con Martha Salotti, su intermediaria ante el periódico, a fin de contextualizar las colaboraciones de la poeta con este medio.
\end{abstract}

Palabras claves: Poesía chilena, Gabriela Mistral, crítica genética, La Nación de Buenos Aires.

Analysis of manuscripts and edition of the poem "Night March" by Gabriela Mistral, starting from the concept of "units of composition" proposed by Jean Bellemin Nöel in the framework of genetic criticism. The article tests a relationship between the original structure of the poem in quatrains constructed with binaries and the call for Latin American union, represented by the friendship between José de San Martín and Bernardo O'Higgins. In the same way, the letters between Mistral and Eduardo Mallea, director of the "Arts and Letters" supplement of the La Nación of Buenos Aires, where Mistral published "Night March", and Martha Salotti, her intermediary with the Argentine newspaper are studied with the aim of contextualizing the collaboration between the Chilean poet and this publisher.

Key words: Chilean poetry, Gabriela Mistral, genetic criticism, La Nación Buenos Aires.

\footnotetext{
${ }^{1}$ Investigación financiada por CONICYT/FONDECYT, perteneciente al proyecto FONDECYT de Iniciación en Investigación No 11161019, "El legado de Gabriela Mistral: reconstrucción y análisis del dossier genético de Lagar" (2017-2018).
} 


\section{INTRODUCCIÓN}

Gabriela Mistral (1889-1957) publicó cuatro poemarios durante su vida², los que incluyeron textos editados previamente en diarios y revistas, sin embargo, algunos de estos textos fueron descartados de los volúmenes de poesía, como es el caso de "Marcha nocturna", poema editado en La Nación de Buenos Aires ${ }^{3}$ el 15 de noviembre de 1942; cabe destacar que este medio publicó diecinueve colaboraciones de Mistral entre 1940 y 1943, catorce de las cuales corresponden a poesía.

La llegada a Chile del legado mistraliano el año 2007 posibilitó el acceso a ochenta y cuatro mil fojas, digitalizadas por la Biblioteca Nacional de Chile. ${ }^{4}$ Gracias a estos manuscritos es factible, por una parte, analizar aspectos de la elaboración de las obras de Mistral; por otra parte, contextualizar tanto la creación poética como la relación de la autora con diversos medios de difusión en los que publicó, a partir de cartas y documentos editoriales.

De este modo, el presente estudio tiene dos objetivos: el primero consiste en profundizar en la relación de la poeta con La Nación a partir de cartas y otros documentos para comprender el contexto en el que Mistral colaboró con este medio, además de acercarnos a sus vínculos con Eduardo Mallea, editor del suplemento "Artes y Letras" de $\mathrm{La}$ Nación, y Martha Salotti, amiga de la poeta. El segundo objetivo es examinar los manuscritos de "Marcha nocturna" y la versión del periódico a partir de la noción de "unidades de redacción", de Jean Bellemin Nöel, referida a los "agrupamientos de frases, más raramente de palabras, que ocupan un espacio definido en las hojas del manuscrito" (2008: 67); se entiende que este término implica un estudio de la producción textual en combinación con la disposición gráfica de la misma. ${ }^{5}$

Es imposible reconstruir a cabalidad el proceso de creación del poema, debido a manuscritos con hojas arrancadas y al posible extravío de documentos; sin embargo, en este caso, es posible recuperar aspectos del contexto histórico y del trasfondo ideológico que condicionan la escritura. El poema se enmarca en el pensamiento americanista de Mistral tanto porque remite a los próceres Bernardo O’Higgins y José de San Martín, como por vincularse a un contexto en el que tenía relevancia visibilizar ejemplos patrióticos. Asimismo, es factible establecer que la estructura original del poema es el cuarteto octosílabo con rima asonante en los versos pares, por lo que consideramos esta estructura la unidad de redacción. A su vez, cada cuarteto se subdivide en binarismos, los que manifiestan la unión

\footnotetext{
2 Desolación (1922), Ternura (1924, reeditado en 1945), Tala (1938) y Lagar (1954).

${ }^{3}$ Desde ahora nos referiremos al periódico como La Nación.

${ }^{4}$ Doris Atkinson cedió a la Biblioteca Nacional de Chile gran cantidad de manuscritos, además de otros objetos personales ("Conoce el legado de Gabriela Mistral en Memoria Chilena" http://www.memoriachilena.cl/602/ w3-article-123325.html).

${ }^{5}$ El trabajo de Bellemin Nöel se enmarca en la "crítica genética", que estudia manuscritos contemporáneos a fin de aprehender los procedimientos creativos de sus autores.
} 
de los héroes y el mensaje latinoamericanista. El análisis de los manuscritos de "Marcha nocturna” comprueba que Mistral parte de la estructura poética, que comunica el significado ideológico, para luego desarrollar los aspectos semánticos.

\section{Gabriela Mistral y sus vínculos con La Nación}

Durante la década de 1940, Mistral colabora con La Nación desde Brasil, pues a causa de la Segunda Guerra Mundial se trasladó a Niteroi en 1940, instalándose en Petrópolis durante 1941. En los ańos siguientes, la impactó el deceso de Stefan Zweig (1942) porque en Brasil desarrolló un vínculo cercano con él y su esposa; no obstante, este dolor no fue tan acentuado como el producido por el suicidio de su hijo adoptivo Juan Miguel Godoy en agosto de 1943, fecha en que interrumpe sus envíos a La Nación por dos ańos.

El lapso 1940-1943 es posterior a Tala (1938) y anterior a la segunda edición de Ternura (1945), que incluye nuevos poemas en relación con la primera edición (1924). Además, la escritora está gestando Lagar (1954) y trabaja en Poema de Chile (1967), en sus "Recados" en prosa, dictaba conferencias y mantenía correspondencia. Es así como entre 1940 y 1943 confluyen diversos proyectos de escritura en su quehacer, a la vez que suceden hechos que marcan su vida y posterior producción poética, destacándose entre estos la muerte de su hijo.

La cercanía con Eduardo Mallea (1903-1982) y la amistad con la educadora Martha Salotti (1899-1980), quien entregaba sus textos a La Nación, propiciaron las colaboraciones de Mistral con este medio. La correspondencia digitalizada entre Mallea y Mistral va desde el 28 de noviembre de 1942 hasta el 27 de noviembre de 1945, más dos cartas sin datar; son nueve cartas y dos telegramas en los que se percibe una relación amistosa, colaboración recíproca y mutua confianza. Mistral elogia a Mallea y a su libro Historia de una pasión argentina (1937) en "Algo sobre Eduardo Mallea" (AE0013092 s.f.) ${ }^{6}$; la fecha de edición del libro permite afirmar que la amistad entre ambos es anterior a las fechas del epistolario digitalizado. Asimismo, consta en los manuscritos del poema "La huella", que este fue dedicado a Mallea, aunque luego la dedicatoria se suprimió, quizás a causa de un malentendido sobre las colaboraciones a La Nación.?

Al constatar que sus colaboraciones se publicaban tardíamente en relación con la fecha de envío, Mistral interpreta que Mallea no está interesado en sus textos. En carta a Mistral, Mallea aduce que la tardanza en publicar se debe a "mi decisión permanente de colocarla en primer término en las páginas” (AE0008184, 05-02-1945: 2); al cotejar las publicaciones, se comprueba lo afirmado por Mallea; también, el editor argumenta su

\footnotetext{
${ }^{6}$ A partir de esta referencia, se consigna el número asignado por la Biblioteca Nacional de Chile a cada manuscrito, para distinguirlos.

7 “La huella” se publicó en revista Sur en 1939 (IX. 54: 17-19), incluyendo la dedicatoria a Mallea.
} 
incomprensión sobre emplear a Salotti como intermediaria, pudiendo enviar Mistral sus colaboraciones $^{8}$. Desde Petrópolis, Mistral escribe a Mallea:

Yo soy un colaborador de 'La Nación' bastante salida del marco tácito e invisible, pero que yo veo muy bien, que es el del 'Suplemento'. Y por saberlo precisamente, por esto, deduzco de ello el que mis artículos no se publican en tres meses como despedidas, o cuando menos, como advertencias. (AE0010890, 14-03-1945: 1)

La poeta arguye que el suplemento, y por tanto, el arte, es de un valor secundario en La Nación. Mistral ya es una poeta de renombre por aquel entonces, por lo que no entiende que no se le publique. En todo caso, el reclamo se resuelve en una promesa-advertencia al final de la misiva: "Irá un artículo cada dos meses a 'La Nación”" (AE0010890, 14-03-1945: 1).

Otra carta de Mistral, sin data pero posterior a agosto de 1943 por la referencia a la muerte de su hijo, plantea el desinterés de La Nación por su trabajo:

Yo escribo ahora algo que no les interesa a Uds. (sic): unos Recados sobre Plantas y Animales -los mas (sic) de Chile. No puedo escribir sobre las cosas de fondo de mi país porque me parecen mal y no puedo decir lo mal que me parece, a causa de ser funcionaria. Y esto es lo mas (sic) decisivo -sólo leer y escribir árboles y animales alivia, refresca y cura un poco mi pensamiento, tan herido como mi alma. La poesía hecha desde Agosto de 43 hasta hoy, son versos para Yin. Se los guardo a 'Sur' (AE0010891, s.f.: 1).

La poeta señala que su escritura está condicionada por el cargo consular, pues este la obliga a restarse de la crítica a los estamentos del poder chileno, y que la poetización de plantas y animales posee un efecto terapéutico en ella, necesario por el duelo; este hecho la lleva a habitar en un Chile del recuerdo, en el que destaca la flora y la fauna. Explicita su relación con la revista Sur, dirigida por Victoria Ocampo, en la que publicó recados y poemas, aunque no todos vinculados a la muerte de su hijo.

Es interesante que para Mistral los diarios no constituían un soporte óptimo para la poesía; considera a los suplementos culturales formatos para reflexiones, ya sea como "recados", ensayos o transcripciones de conferencias. El 6 de abril de 1951 confiesa a Ocampo:

Mallea me pedía versos y no prosa. Y hallo muy extraña la poesía sobre un periódico. Sigo haciendo versos, pero después de cinco años de acabado Yin. Porque tengo,

\footnotetext{
${ }^{8}$ El epistolario deja entrever un enrevesado sistema de envío a través de Salotti, y luego empleando una agencia colombiana. En 1945, la poeta aduce desconocimiento sobre qué medio recibe sus textos, quizás icon una velada ironía? creyendo que Mallea no quiere publicarla: "No sé qué diario de Bs. Ais. (sic) es el que recibe mis artículos de la agencia colombiana" (AE0010892, 28-04-1945: 1).
} 
ahora, cierta ilusión de que lo alcanzo y de que viene cada vez que lo necesito.... y la poesía del último tiempo -hay un libro, Lagar es muy poco "para la gente" de periódicos. (Mistral y Ocampo 2007: 198, cursivas y comillas del texto)

Aparte de sus reparos con el formato, Mistral identifica un tipo de lector y de editor vinculado a los periódicos que no concuerda con los lectores de poesía; en este sentido, su Lagar, aún inédito en esa fecha, es "muy poco"; la poeta comenta además que su duelo la ha mantenido cinco años dedicada a "Yin" (su hijo) - ¿sin escribir poesía? o ¿escribiendo sobre Juan Miguel únicamente?- y que ha retomado los versos en la medida en que ha experimentado una cercanía con el espíritu de su hijo. Sus cuadernos manuscritos refieren estas experiencias paranormales y rezos dedicados a Juan Miguel.

A diferencia del vínculo con Mallea, la amistad entre Martha Salotti y Mistral se mantuvo hasta la muerte de la poeta. El epistolario digitalizado consiste en doscientas doce cartas y cuatro telegramas; las cartas se ubican entre 1941 y 1957, pero algunas están sin datar; la más antigua del legado (Salotti AE0021668, 15-05-1941) evidencia que la amistad entre ambas ha comenzado antes de esta fecha, pues Salotti refiere envío de encargos de la poeta. Mistral escribe sobre Salotti "Recado sobre una maestra argentina" (AE0015162, s.f.), en el que recuerda que: Salotti se convirtió en "mi correo argentino de noticias, de libros y hasta de medicinas" (s.f.: 1).

El epistolario evidencia que Salotti supervisó los asuntos editoriales de Mistral en Argentina; aparte de las colaboraciones a La Nación, revisó las segundas ediciones de Ternura, por Espasa-Calpe (1945) y de Tala por Losada (1947), defendiendo con ímpetu los derechos de la autora, lo que generó una tensa relación entre ella y los editores. En una carta enviada a Mistral desde Losada, el editor Guillermo de Torre acusa a Salotti de exceso de celo (AE0012395, 11-12-1946: 1-2); por su parte, Salotti manifiesta en sus cartas una desconfianza generalizada del mundo editorial y su percepción de que Mistral poseía escasa habilidad para manejar asuntos de dinero. La revisión de los contratos de la poeta deja a Salotti con la impresión de injusticias en relación con los derechos de autor, por lo que le solicita a Mistral los contratos con Saturnino Calleja de la primera edición de Ternura, y con la Editorial Aguilar (Salotti AE0009081, 01-06-1944: 2). Más adelante le pedirá a Mistral "Le ruego no firmar contrato alguno sin mi intermedio" (Salotti AE0009119, 1612-1945: 2).

Teniendo en cuenta este afectuoso epistolario, sorprende leer en una carta de Mistral a Victoria Ocampo: "Martha Salotti no es grata para ti -tampoco lo es para mí, Victoria" ("s.f. pero después de 1955", Mistral y Ocampo 2007: 277). La poeta buscaba un intermediario para sus cartas porque teme interferencias ante la falta de respuestas de Ocampo, sin embargo, ella escribe que sí las recibe y las responde (04-01-1956, 2007: 278), de modo que esta preocupación puede deberse a sus problemas de memoria ya frecuentes en esta época. Imposible saber si la supuesta aversión por Salotti de ambas escritoras también remite a ese problema. 


\section{El proceso y EL CONTEXTO DE PRODUCCión dE "MarCha NocturNA"}

"Marcha nocturna" revela la admiración de Mistral por Bernardo O' Higgins y José de San Martín y se inscribe en la temática americanista desarrollada por la autora en prosas, Tala y Poema de Chile. Durante la Segunda Guerra Mundial, la poeta recibe una carta de Pedro Aguirre Cerda, presidente chileno de la época, en la que se evidencia la preocupación de ambos por entregar "modelos positivos" a la juventud con respecto del amor por la patria:

Comparto su opinión de que hay que dotar de un alma que vitalice a la juventud. Es preciso crear el mito de la nacionalidad para dar a nuestros pueblos el impulso que hizo grandes a Inglaterra, Francia, Estados Unidos y Alemania (...) En este tiempo de "Quintas Columnas" he creído prudente iniciar una campaña para fortificar el sentimiento patriótico y, al efecto, hoy he presidido una reunión que tuvo por objeto buscar la forma de relievar ante el país y ante la juventud, especialmente, la figura de O' Higgins, así como han sabido hacerlo los argentinos con San Martín, del que no desmerece nuestro héroe máximo. (AE0006335, 27-05-1940: 1)

De las palabras de Aguirre Cerda se colige la admiración por los países que participaban del conflicto bélico del momento, sin reparar en que la asimilación de modelos europeos es problemática. Sin embargo, aun con su entusiasmo por países más "desarrollados", propone un modelo cercano como objetivo político: la mitificación de Bernardo O'Higgins de forma similar al ensalzamiento de José de San Martín en Argentina.

El Presidente continúa argumentando a Mistral que "hemos venido sońando con la ruta que dejó trazada el gran Bolívar y que no ha podido fructificar por el suicida egoísmo lugareño en estas repúblicas" (Aguirre Cerda AE0006335, 27-05-1940: 1-2); el afán por la unión latinoamericana explica la intención de hermanarse con Argentina al vincular a dos figuras del periodo independentista de América, aliados durante la campaña del Ejército Libertador de los Andes (1816-1824).

Es importante destacar que Bernardo O'Higgins ha sido emblema de diversos sectores políticos; en especial, persiste en el imaginario chileno la asociación entre Augusto Pinochet y O'Higgins. No obstante, ideologías de izquierda también han reconocido cualidades en el prócer. Salvador Allende y Fidel Castro establecen en sus discursos una línea de continuidad entre O’Higgins, Bolívar, San Martín y Martí, como actores de la independencia del continente. ${ }^{9}$ El Partido Radical de Chile, al que perteneció Aguirre Cerda,

\footnotetext{
${ }^{9}$ Guerrero y Cárcamo (2013) afirman: "la consideración que puede hacerse respecto del significado cultural de un personaje como O’Higgins es tremendamente versátil. Al tratarse, en definitiva, de paradigmas permanentes y de virtudes amplias y universales, carentes de signo político contingente posterior, pueden ser tomados como ejemplos por grupos de ideologías absolutamente opuestas" (133).
} 
también valora a O’Higgins, por su rol de libertador. ${ }^{10}$ Este es el O’Higgins admirado por Mistral, forjador de la independencia latinoamericana.

Además, Mistral comparte el respeto por O’Higgins; es el único prócer al que nombra en Poema de Chile, en el que aparece como niño en el poema "Chillán" (2009b: 664-667), al igual que en un poema inédito e inconcluso titulado "Recado" que se complementa con el hológrafo "O 'Higgins” (AE0014213, s.f.), parte del futuro Poema de Chile ${ }^{11}$ o versión preliminar de "Chillán"; en este se evoca la niñez del héroe encumbrando cometas, observando la naturaleza y durmiendo en el regazo materno; se le llama "El Niño de la Esperanza" (v.8, s.f.: 1) y se le describe como "mesticillo ojos azules mansos los ojos de lino / hombros altos, y duras las cejas bravas" (vv.9-10, s.f.: 1). Mistral se enfoca en la fusión de lo europeo y lo americano en la figura del prócer, en su cercanía con la madre, y en su relevancia para Chile, en tanto es "la Esperanza". Poetizar la infancia de O’Higgins humaniza su figura, alejándolo de representaciones simbólicas oficiales.

La poeta estudió a O’Higgins como consta en el manuscrito [Cuadernos] [Poesía, prosa y notas] (AE0015368, s.f.: 2-4), y en una carta de Gregorio Amunátegui (1901-1981) (AE0006593, 08-09-1942) con un resumen sobre O'Higgins redactado por Domingo Amunátegui (1860-1946), historiador y tío de Gregorio Amunátegui. Los subrayados de Mistral en el texto indican los aspectos que destacaba del héroe: en cuanto a lo personal, la condición de hijo no reconocido por el padre y la voluntad asistir a su madre; en cuanto a su rol histórico, el ideal independentista sobre Chile, Argentina y Perú; la falta de entrenamiento militar, compensada con valentía; el fracaso en el sitio de Chillán y los errores de estrategia en la batalla de Rancagua, en la que de igual modo obtiene la gloria; su amistad con San Martín y la visión americanista de ambos, la formación del Ejército de los Andes, y la satisfacción de O’Higgins luego del cumplimiento de sus sueños de libertad.

Asimismo, durante una visita a Lima, Mistral dicta una charla sobre el héroe chileno y sus vínculos con Perú: "O’Higgins, símbolo en la gesta de la emancipación y de la amistad del Perú y Chile”, incluida en el volumen Recados contando a Chile (Mistral 1957: 179-182). En este texto, Mistral enfatiza la hermandad entre países americanos, el agradecimiento a Perú por recibir a O’Higgins en 1823, puntualizando que el prócer no fue un "desterrado" de Chile "porque no hay destierro dentro del Continente" (Mistral 1957: 181) de lo que se deduce la idea de América como una sola patria.

La amistad entre O’Higgins y San Martín es significativa para Mistral en tanto encarna su ideario de unión latinoamericana; asimismo, cautivaron la atención de la poeta el desprecio social experimentado por ambos en el marco de sociedades elitistas y prejuiciosas -O’Higgins por su condición de "hijo natural” y San Martín por su tez morena,

\footnotetext{
${ }^{10}$ Por ejemplo, Gabriel González Videla compara a quienes resistieron el dominio español con el Frente Popular: “caerán desplomadas [oligarquías americanas] y hecho trizas, como cayó el Imperio español (sic), bajo la gloriosa solidaridad de los pueblos americanos inspirados por Bolívar, O’Higgins y San Martín” (González Videla 1938: 24).

${ }^{11}$ El manuscrito consta de cinco hojas, pero las hojas 3 y 4 corresponden a un poema sobre Alonso de Ercilla, también inédito y parte del proyecto de Poema de Chile; solo las hojas 1, 2 y 5 remiten a la figura de O’Higgins.
} 
que motivó suspicacias sobre su origen- ${ }^{12}$, además de sus muertes en el extranjero -Perú y Francia respectivamente-, final que vaticinaba para sí misma.

"Marcha nocturna" se construye desde la admiración por estos próceres y el ideario americanista; además, Mistral incluye en el texto uno de sus motivos recurrentes, el fantasma, aunque en algunos versos se torne ambigua la configuración de los héroes como tales, debido al estrecho vínculo con la historia; podría ser este un fragmento de los trayectos de O’Higgins y San Martín durante la campaña del Ejército Libertador de los Andes. Sin embargo, las figuras de los próceres se complementan con la poetización de la pampa durante la noche, espacio-tiempo que sugiere la fantasmagoría, así como la presencia de muertos que perciben el paso de ellos y del "ascenso" de los héroes en el final del poema. A continuación se reproduce la versión de La Nación: ${ }^{13}$

Marcha nocturna

1 Por la Pampa de la hierba

2 y del viento de la fe,

3 los Padres nuestros caminan

4 cargados de amanecer.

5 San Martín con O’Higgins

6 pasan como Abel y Set,

7 uno quemado de sales,

8 el otro abandonado en mies.

9 Y cuando se les escucha

10 preguntar o responder.

11 Se les juntan los costados

12 como a laurel y laurel.

13 El pampero ni la hierba

14 triturada de sus pies

15 saben decir de sus Padres

16 cuál más herido y más fiel.

17 La vieja Pampa sabuesa

18 obedece su querer

19 y no les para ni ataja

20 con monte ni con mies.

21 Van pasando tan ligeros

\footnotetext{
12 "Desde nińo, debido al tono de su piel, a que su familia no era poderosa, o simplemente porque era verdad, San Martín enfrentó habladurías que atribuían un origen indígena a su madre o su padre" (Sepúlveda 2007: 269).

${ }^{13}$ Una versión de "Marcha nocturna" se editó en Almácigo (Mistral 2009a: 40); sin embargo, esta última versión no corresponde a la del periódico, ni a los hológrafos digitalizados.
} 
22 como el que no quiere ser 23 y a más apuran el paso

24 hierven como el hidromiel.

25 Hierven la noche y el Plata, 26 hierve del quererlos ver

27 y los muertos, en su jarro

28 de arcilla, hierven también.

29 Cuando detienen la marcha

30 en lugar de dos se ve

31 un solo flanco que ciega

32 y un agua bajando de él.

33 Agua con ojos de Padre

34 que hace llorar al beber

35 y se bebe y más se bebe

36 en la tremenda embriaguez.

37 Y retomando la marcha

38 se van dejando caer

39 por los quiebros de la noche

40 orugas de amanecer,

41 y bayas, y prietas valvas

42 que echan luces de través,

43 y caracoles volteados

44 a mar que aun no se ve.

45 La costa se abre en granada

46 de rutas, al comprender,

47 y no se detiene a sus Padres

48 con duna ni olas de hiel.

49 Ninguno los vió venir

50 ni les ve desparecer

51 y tejerse y destejerse

52 a la señal de Miguel.

53 Suben rayados del alba

54 cuando el sol les da en la sien

55 y la tierra se nos queda

56 como la tienda de Ismael.

57 Carne y carne, puerta y puerta

58 que vieron y ya no ven 
59 otra vez ahora esperan

60 en la costa de la sed.

61 Vueltos a noche y a dunas

62 aguardan oír y ver

63 la remada y el despeño

64 de un petrel y de un petrel.

Petrópolis, octubre de 1942.

En su contenido, "Marcha nocturna" evidencia similitudes con "La cabalgata" de Tala porque en ambos se poetiza el tránsito nocturno y fantasmagórico de héroes, y se alude al petrel, ave que deambula cerca de los mares, de tal modo que la caminata de "Marcha nocturna" implica el traslado desde la Pampa hacia el mar; en el poema de Tala, la cabalgata de los héroes se acompaña de estas aves: "Con el vuelo remado / de los petreles pasa” (vv. 7-8, Mistral 2009b: 335). Las alusiones a la geografía y a los héroes son específicas en "Marcha nocturna", ya que San Martín y O'Higgins viajan por un territorio recorrido durante sus campañas, la Pampa, mientras que en "La cabalgata" se emplea el concepto de "héroes" sin individualizar a ninguno y el espacio transitado es la "Tierra". Esta indicación geográfica general, sumada al protagonismo de la noche, propicia en "La cabalgata" un ambiente fantasmagórico más palmario. ${ }^{14}$

La versión publicada en La Nación de "Marcha nocturna" tiende al octosílabo polirrítmico con rima asonante en los versos pares (/e/); estos versos finalizan en palabras agudas, por lo que el metro octosílabo se conforma como $7+1$, mientras que los impares finalizan en palabras graves; si bien el esquema de la rima es regular, la métrica no: de los sesenta y cuatro versos, sesenta son octosílabos, dos son heptasílabos (versos 5 y 20) y dos son eneasílabos (versos 47 y 57). En los hológrafos se mantiene la tendencia a escribir en octosílabo y la rima asonante, pero existen diferencias en cuanto a la poetización de algunos elementos, a la división de las estrofas, y a la distribución de los versos en estas. Aparte de considerar el cuarteto como la unidad de redacción y la elaboración de binarismos, se distinguen en el análisis cuatro núcleos de significación, a fin de organizar el comentario:

\footnotetext{
${ }^{14}$ No se han encontrado documentos de "La cabalgata", por tanto resulta imposible compararlo con "Marcha nocturna". Los manuscritos de "La cabalgata" son: ([La cabalgata] [manuscrito] AE0013621, 4 hojas), copia del poema de Tala, sin pie de página, ni dedicatoria; dos estrofas de "La cabalgata" en [Archivador 13] (AE0015397: 50), archivo del que fueron arrancadas hojas; por último, un recorte de Nuestro Diario, de Guatemala (AE0016060, 10 de noviembre de 1945), en el que se observan mínimos cambios lexicales y de puntuación con respecto a Tala; se destacan: "partiendo hacia la noche" (Diario) / "partiéndose la noche" (Tala) (v.3), "y lo ondeo en el aire" (Diario) / "y lo hondeo en el aire" (Tala) (v.73). En el primer caso, el verso de Tala indica una condición de la noche, mientras que el de Nuestro Diario se refiere a la dirección de la cabalgata; esta va "hacia" la noche. El verso 73 del periódico remite a agitar o mover al nińo (vv.69-70) haciendo ondas para que la cabalgata lo vea y se lo lleve, mientras que en Tala la forma verbal "hondeo" puede referirse a lanzar al niño cual si fuese con una honda. Considerando la fecha del periódico, podrían corresponder a cambios realizados en forma posterior a la edición de Tala.
} 
la pampa, la caminata, la unión de los héroes y la transformación de la materia en espíritu (fantasmas).

Los manuscritos del poema son cuatro hológrafos escritos por la poeta, tres de los cuales se encuentran en Cuadernos de poesía: el manuscrito "Marcha nocturna" (AE0015005, s.f., 4 hojas), el manuscrito del [Cuaderno 33] (AE0013046, revisado en 1948: 169-170), sin título ni fecha de escritura e incompleto, probablemente por hojas arrancadas, el manuscrito del [Cuaderno 129] (AE0015292 revisado en 1948: 102-118,125-137 y 159), sin título ni fecha de escritura, y el manuscrito del [Cuaderno 503] (AE0015265 revisado en 1948), sin data de escritura, en el que se encuentran cuatro versiones del poema (1220, 74-85, 86- 89 y 90-97 y 99); en las tres primeras versiones el poema se titula "Marcha nocturna", pero en los índices del Cuaderno el texto aparece con los nombres de "Viaje nocturno" y "San Martín y O'Higgins" (1) ${ }^{15}$; en la cuarta versión, el poema se llama "Viaje nocturno" (90). Además de estas versiones, se encuentran reescrituras de estrofas (71-73). De esta manera, los cuatro manuscritos corresponden a siete versiones. ${ }^{16}$

Si bien la versión de La Nación presenta seis estrofas conformadas con diversas cantidades de versos, cada una de las estrofas se estructura en base a cuartetos reunidos en ellas. La primera estrofa contiene cuatro cuartetos, la segunda y la cuarta tres, la tercera, la quinta y la sexta dos cuartetos por cada una. Si se examinan los manuscritos conservados se comprueba que la estructura original del poema fue en cuartetos, los que Mistral decidió unir para La Nación en unidades mayores de sentido. A su vez, los cuartetos se construyeron en base a dísticos; es decir, dos versos conforman una oración enlazada al dístico siguiente, a partir de signos de puntuación o de la conjunción "y". Estas últimas conectan oraciones compuestas copulativas; también se observan dos o cuatro oraciones en el interior de un cuarteto o una oración con un extenso complemento. Asimismo, en la mayoría de los dísticos se observan binarismos, por lo que la forma del poema se corresponde con su contenido: la poetización de dos héroes.

Estas estructuras binarias son elaboradas con términos diferentes, sin ser necesariamente antónimos, sino más bien complementarios; así por ejemplo, hierba y viento (vv.1-2) que se corresponden con las coordenadas abajo-arriba de la pampa; también se forman de términos que sin ser sinónimos, apuntan al mismo significado; tal es el caso de Abel y Set (v.6), hermanos que no se oponen entre sí, sino a Caín, el hermano fratricida. Los personajes benignos del relato son escogidos para metaforizar a los próceres, lo que implica la similitud ética entre ellos, sin desconocer que ambos son personas diferentes, como también se sugiere con el binarismo sales-mies, en el que el primer elemento representa a O'Higgins por el mar chileno, y el otro a San Martín, por las plantaciones de cereales en Argentina. Además se encuentran binarismos anafóricos, los que remiten a la similitud de

\footnotetext{
${ }^{15}$ En la digitalización del Cuaderno, la página 1 se encuentra entre la 19 y la 20. Es posible que estuviese desprendida en el momento de la digitalización, pero dentro del Cuaderno, y fue ubicada en ese espacio.

${ }^{16}$ Se entiende por manuscrito el documento -en este caso en [Cuaderno 503]- y lo diferenciamos del concepto de versión, que remite a una propuesta alternativa para un poema específico.
} 
los héroes: laurel-laurel (v.12), petrel-petrel (v.64). Es interesante que la marcha de los héroes se poetiza como hidromiel en ebullición, pues esta bebida es en sí un binarismo por estar compuesta de agua y miel, de modo que evoca la naturaleza distinta pero complementaria de los próceres. Solo dos parejas son antónimas, tejerse-destejerse (v.51) y vieron-ya no ven (v.58), pero dado el contexto no funcionan como tales, sino que remiten a la condición fantasmagórica de los próceres, de "ser y no ser": por una parte, estos se tejen y destejen en la velocidad de la marcha, por otra parte, la vista de la materia (carnes y puertas) de la que se disfrutó (en vida) es imposible por el imperativo del ascenso. Se deducen además los binarismos agua-tierra, río-pampa ${ }^{17}$, y noche-alba, que conforman el "escenario" de texto. El primer binarismo se vincula con el motivo de la sed, y el tercero con el tránsito de los próceres desde la carne hasta el espíritu. ${ }^{18}$

El poema sugiere el desplazamiento de los héroes a partir de verbos en presente, infinitivos, gerundios y a la organización de una secuencia de acciones enmarcada en una acción continua, la caminata. Los héroes se juntan para conversar; son percibidos por pampero y espacio; los héroes y lo que les rodea "hierven", incluso los muertos que los perciben; se detienen para transformarse en agua y/o beber; retoman la marcha hacia la costa; ascienden, lo que coincide con la llegada del alba; la gente ("carne y carne") espera verlos. Durante la marcha confluyen los cuatro elementos: tierra, agua, aire (viento pampino) y fuego (acción de hervir), sugiriéndose con ello una especie de alquimia en la que los próceres se despojan del cuerpo y devienen en espíritu.

En el [Cuaderno 33] el poema aparece en uno de los índices (AE0013046, 1948: 6) que señala su ubicación en la página 116, lo que no es efectivo, sin embargo, figuran cinco cuartetos en las páginas 169 y 170, enumerados desde el 16 hasta el 20. Estas estrofas remiten al contenido de la última estrofa de la versión de La Nación, ${ }^{19}$ lo que sugiere un borrador más largo y la pérdida de hojas, pues es un fragmento sin titular y que limita en las páginas

\footnotetext{
${ }^{17}$ El río de la Plata se ubica en un sector distante de la Pampa, y en la época de los próceres, Pampa y río pertenecían a dos organizaciones distintas: la Pampa a la Provincia de Buenos Aires y el sector del río a las provincias Unidas del Plata. El espacio conformado por Mistral no obedece a la geografía, sino que es una elaboración simbólica de un lugar fantasmagórico.

${ }^{18}$ Los binarismos en orden de aparición son: hierba-viento, San Martín-O’Higgins, Abel-Set, sales-mies, laurellaurel, pampero-hierba, herido-fiel, monte-mies, noche-Plata, flanco-agua, bebe-bebe, duna-olas de hiel, tejersedestejerse, carne-carne, puerta-puerta, vieron-ya no ven, noche-dunas, oír-ver, remada-despeño, petrel-petrel. Un binarismo implícito es el de los versos 53-56: los héroes suben-la tierra se empobrece al perderlos.

${ }^{19}$ Los cuartetos enumerados 16, 19 y 20 son variantes de los versos 61 al 64 de la versión de La Nación. A las tres estrofas las conecta la imagen final de los dos petreles. Las estrofas 19 y 20 coinciden en la actitud de esperar a las aves. En cambio, la estrofa 16 manifiesta la identificación de los próceres con los petreles, en tanto estos ascenderán de la costa hacia el cielo: "Otra vez dejan la costa / del salitre y de la mies, / para sumirse en el cielo, / el petrel con el petrel” (AE0013046 1948: 169). El cuarteto 17 resulta una variante de los versos 53 al 56 de la versión de La Nación, con la única diferencia de explicitar el referente de la comparación entre la tierra sin los héroes y la tienda de Ismael, la pobreza: "dejando pobre la tierra / como la tienda de Ismael" (AE0013046 1948: 170). Por último, el cuarteto 18 constituye una variante de los versos 57 al 60 de la versión de La Nación, diferente solo en un signo de puntuación: una coma final en el verso 58 del texto publicado en el periódico.
} 
anteriores y posteriores con caóticos borradores asociados al Poema de Chile, estado muy diferente del que se observa en estas estrofas, con seguridad copias de un borrador anterior por la falta de enmiendas, a lo que se añade la métrica octosílaba uniforme de los versos.

En el manuscrito "Marcha nocturna" (AE0015005, s.f.) se distinguen nueve cuartetos completos y cuatro incompletos, dos quintetos (uno incompleto) y dos dísticos, uno de ellos incompleto. El dístico terminado se dispone de manera vertical al igual que un cuarteto en la última hoja. Se mantiene la rima asonante en versos pares y los versos son octosílabos a excepción de dos heptasílabos y de los versos incompletos. En cuanto a los núcleos de significación se distingue el trabajo con la poetización de la Pampa y de la primera parte de la caminata, pero no se encuentra el momento del hervor de los elementos, de beber ni de caminar hacia la costa, sino que luego de la poetización de la Pampa, los héroes ascienden y la gente espera verlos.

En este manuscrito es explícita la configuración de los héroes como fantasmas: "Por la Pampa desvalida / que se cruza y no se ve / los Padres muertos caminan / cargados de anochecer" (vv.1-4, s.f.: 1). Obsérvese además el cambio en la adjetivación entre esta versión y la de La Nación; en el manuscrito, la Pampa está personificada como un ser vulnerable ante los fantasmas, condición que desaparece de la versión del periódico; también, la sustitución de "anochecer" por "amanecer" en esta versión evidencia la idea de que los héroes han caminado durante toda la noche.

La comparación entre este manuscrito y la versión de La Nación muestra que los elementos "hierba" y "viento" de los versos 1 y 2 de La Nación fueron desplazados hacia el inicio desde una estrofa posterior y reescritos en la poetización de la Pampa. En el manuscrito se lee: "Hierbas y viento no saben / cuál de los dos el mas (sic) fiel / No les distinguen pasando /los alientos ni sus pies" (vv.12-15, s.f.: 1). Ambos elementos son parte de la Pampa en los dos textos pero en la versión de La Nación se comprime la imagen de la geografía -Pampa es hierba y viento- desechándose la personificación de la misma en el primer verso ("desvalida"); solo se personifica la Pampa en el verso 17 "La vieja Pampa sabuesa", verso que se encuentra también en el citado manuscrito.

Parte del método de Mistral es reescribir versos o estrofas de forma inmediata a la primera redacción de los mismos. En el manuscrito, los versos 5 a 8 corresponden a dos versiones de dos versos; además, es notoria la existencia de una tercera versión borrada, pues los versos 5 y 6 fueron elaborados encima de borrones: "dicen que pasan iguales / la Pampa el at Seth y el Abel /San Martín con O'Higgins /pasan en Abel y Seth," (vv.5-8, s.f.: 1). La versión de $L a$ Nación muestra una variante de los versos 7 y 8 del manuscrito: "San Martín con O'Higgins /pasan como Abel y Seth," (vv.5-8, s.f.: 1). Se define con mayor nitidez la comparación entre los próceres y los hermanos menores de Caín al utilizar la conjunción "como" y desechar "en", la que podría leerse como: comparativo, sinónimo de "con" (una acepción en desuso de "en" como pronombre), o "transformado en", que crearía una identificación entre los héroes y los personajes bíblicos.

Se observan además binarismos que se descartaron de La Nación: metales-mies (vv.9-10, s.f.: 1) para representar a los héroes; alientos-pies (v.15, s.f.: 1), expresados como 
ausencia porque estos no se distinguen en la marcha fantasmagórica; "preguntar o responder" (v.19, s.f.: 2) disyuntiva sobre la actitud de los héroes al dialogar; "Nadie sabe nadie dice" (v.23, s.f.: 2), referido a que es imposible saber cuál de los héroes es más fiel; y un binarismo que establece un vínculo entre el escenario y los héroes: "A Mas (sic) se cierra la noche / mas (sic) se apura su querer" (vv.30-31, s.f.: 2).

El manuscrito del [Cuaderno 129] (AE0015292, 1948) es el menos estructurado, pues no se observa una organización del poema, sino un conjunto de estrofas, en su mayoría cuartetos, sin articulación entre sí; el título no se consigna en el texto, y quien revisó el Cuaderno calificó el texto como "notas" y no como versión: "Hay aquí notas sobre Marcha Nocturna" (2). Los versos se presentan disgregados a lo largo de varias páginas intercaladas con ejercicios de rimas (113 y 115, 150-158), una versión del poema "Ciego" (119-124), y otras estrofas sin titular (138-149).

Sí se constata que Mistral sigue un formato: cuartetos octosílabos con rima asonante e-e en los versos pares, lo que implica que se establecieron elementos rítmicos, a partir de los cuales construye el imaginario del texto, reescribiendo una o dos veces de forma inmediata para introducir variantes léxicas y ajustes métricos. Se identifican treinta y cuatro cuartetos completos pero con ajustes métricos pendientes, algunos numerados con la intención de organizar el poema, un quinteto, un sexteto, tres versos solos y trece cuartetos fragmentarios porque se borraron versos o nunca fueron concluidos. Llaman la atención dos estructuras de cuartetos carentes de contenido semántico significativo esbozadas con verbos, nexos, líneas punteadas, y frases escritas después de la estructura, pero ubicadas en el inicio de cada estrofa, que manifiestan la voluntad de ceñirse a esta forma estrófica y a la estructura binaria:

blandas

Las mas

Las mas......

pasan y pasan

en y en

de las cascadas

Vienen det...............

y....... de..............

o del.

(AE0015292, 1948: 136)

Si bien podría pensarse que una poeta como Mistral configura el contenido de un poema de forma previa a diseñar una estructura, lo cierto es que los manuscritos demuestran la operación inversa: la fijación de una estructura en el marco de la cual se va adaptando el desarrollo del tema. 
En este manuscrito (AE0015292, 1948) se distinguen binarismos que individualizan a los héroes: dorado-blanco (107), mies-sal y pez (107), Lima-Boulogne Sur Mer (109) -sus lugares de fallecimiento-, pampero-montańés (128); binarismos que los reúnen: batallas de Chacabuco-Maipo (112), corazón-cuerpo (125), Cristo-Miguel (110), quienes les entregan las espadas; binarismos espaciales: pampa-pacífico (105), que remite al origen de los héroes; noche-santo río (112); puertas-cerrojos (126); mirra-ciprés (130); "la costa de tos los salitres I y ta costa de la mies" (159), que identifica a los héroes y se condensa en la versión de $L a$ Nación en "sales-mies"; y binarismos de la transformación de la materia en espíritu: "siendo el ser en el no ser" (106), su reescritura "pujando al ser y al no ser" (116); rectos-azules (131), espíritus de los héroes; antes-después y hoy-ayer (112), adverbios temporales, pero que en este contexto eternizan el diálogo de los héroes. Al igual que en el manuscrito anterior, la condición fantasmal de los héroes es explícita, así como también la ideología americanista: "Es como si ya fue todo / pero todo vuelve a ser / como si el Adán de Am.[érica] / nunca deja de nacer" (133). En esta estrofa, ausente en La Nación, la transformación de los cuerpos en espíritus evoca un renacimiento del "espíritu" americano, representado en los próceres.

Como se reseńó, el manuscrito del [Cuaderno 503] (AE0015265, 1948) se divide en cuatro versiones a las que se agregan anotaciones. La primera versión (12-20) posee la nota "No borrar"; consta de dieciséis cuartetos enumerados y de dos anotaciones en páginas izquierdas o reversos de hojas. En este y en los otros manuscritos es evidente que Mistral escribía versos organizados en estrofas y en poemas en la página derecha del Cuaderno o anverso, mientras que los reversos (páginas izquierdas) se destinan a reescrituras de uno o dos versos puntuales, a variaciones lexicales, $\mathrm{u}$ a otro tipo de notas en las que se expresa mayor libertad con respecto a la disposición gráfica de la página, a diferencia de la versificación estricta en las páginas derechas. En este caso las notas corresponden en primer lugar a estrofas con tachaduras y sin enumeración en las que se asocia a los héroes con el río:

\section{huemul \\ río-hrateón}

dutee río
río patoma-...) (AE0015265, 1948: 17).

O’Higgins se representa como río-halcón, ave que luego se reemplaza por huemul, animal del escudo patrio que evoca la humildad, mientras que en la misma línea San Martín se representa como río-paloma, evocando paz o mansedumbre. En segundo lugar, la otra anotación configura a los héroes como fantasmas; Mistral altera en ella la rigidez del cuarteto para reescribir un verso en el extremo superior derecho: "eomo la eseama det pez / con temblor de niebla o pez" (19, centro de página); como en las / dunas el pez" (19, extremo superior derecho de la página). Es así como en los escasos reversos de la página comunican una dimensión puramente semántica, o de variantes léxicas, mientras que en los anversos hay una mayor preocupación por todos los niveles del texto, partiendo de la forma estrófica y la rima.

Aspectos interesantes de esta versión tienen que ver con que la ausencia de la pampa y su reemplazo por la "Casa de los Niños" (13), metáfora del espacio de tránsito entre la 
carne y el espíritu, que se acompaña por las imágenes de la noche y del río Plata. Esta imagen se adjetiva en un cuarteto posterior como "La casa de ochenta puertas" (14); la oposición interior-exterior es poco relevante en la versión de La Nación, pues solo en la última estrofa se refiere a casas en oposición a la pampa y la costa; a diferencia de ello, en esta versión es importante porque el cuerpo de los héroes se proyecta en esta casa de la que saldrán volando libres como petreles. Otro aspecto consiste en la explicitación del traspaso de cuerpo en espíritu: "Mano a mano van cruzando / x en- con bulto de hombre a laurel" (13).$^{20}$ Se percibe cómo los héroes van atravesando una geografía tanto física como espiritual. También es más específica la identidad de los muertos que ven pasar a los próceres: " $\mathrm{x} y$ locos soldados de Maipo / x hierven en - dentro de la tumba fiel” (14).

La segunda versión del Cuaderno (74-85) es similar a la primera, pero no es una corrección, sino una nueva versión en la que aparecen variantes de las estrofas de la primera versión y se integran otras estrofas basadas en los núcleos de significación descritos, a excepción de la pampa reemplazada con "Casa de los Niños": caminata, héroes unidos, transformación de la materia ${ }^{21}$; se enumeran algunos cuartetos -del 1 al 16-, algunos se tachan, y faltan los números 9 y 10. La tercera versión (86-88) consta de seis cuartetos enumerados más uno tachado. Se observan los cuatro núcleos temáticos pero es una versión incompleta (su último verso termina con coma). Por lo mismo, la ascensión de los héroes no aparece, solo se poetiza hasta que se transforman en "morada nevera" (88) como imagen alternativa al río en el que devienen en la versión de La Nación. Es destacable la adjetivación de la Pampa como "Pampa de milagros" (v.1, 86) y "niña y sabuesa" (v.13, 87), expresión opuesta a la de "La vieja Pampa sabuesa" (v.17) de La Nación. La imagen de la pampa niña parece una imagen intermedia entre "Casa de los nińos" y pampa, espacio que se fijará en la versión del periódico como espacio de transformación espiritual.

Por último, la cuarta versión del Cuaderno (90-96 y 99) es similar a la de La Nación con algunas variantes léxicas y de puntuación ${ }^{22}$, lo que sugiere que esta fue la versión que Mistral depuró para el periódico, ya que se observan enmiendas que fijan versos del modo

\footnotetext{
${ }^{20}$ La cruz inicial del segundo verso y en las citas siguientes indica la insatisfacción de la autora con el verso y su voluntad de transformarlo u omitirlo; en este caso quizás, de optar por una de las dos preposiciones expuestos como alternativas.

${ }^{21}$ Es interesante en esta versión que la ascensión de los próceres deja a la gente "como huérfanos" (84), explicitando su condición de Padres de la Patria.

22 Diferencias de puntuación: falta de comas finales en los versos 2, 6, 7, 42 y 46; falta de puntos finales en versos 8, 12, 16, 20, 40, 44, 48, 52, 56, versos que finalizan cuartetos. Variantes de conectores: "pasan en Abel y Seth" (v.6), "como a laurel con laurel" (v.12), "ni con monte ni con mies" (v. 20), "por la señal de de volver Miguel" (v.52) "como tienda de Ismael" (v. 56, omisión de "la"). Variantes léxicas: "cargados de anochecer" (v.4), "X Cuando uno a otro se oye" (v.9), "Tan ligeros van pasando / como quien no quiere ser / pero aunque vayan ligeros" (vv.21-23, el verso 21 fue reorganizado y en el 23 se suprime "ligeros" para La Nación, evitando repetir), "a sorbos de vieja sed" (v.36), "Cuando retoman la marcha” (v.37), "hacen un mar que aún no se ve" (v.44); bajo el verso 48 se escribe "marejada" quizás como alternativa de "olas"; "esperan oír y ver" (v.62).
} 
en que aparecen en La Nación. ${ }^{23}$ Siendo la versión más parecida, llama la atención que también esté escrita en cuartetos enumerados, y estos no se agrupen como en la edición del periódico, lo que nos permite elucubrar en que este último cambio se realizó en la versión mecanografiada enviada a La Nación, que no se encuentra en el legado.

\section{Conclusiones}

El estudio del contexto de producción y de los manuscritos del poema "Marcha nocturna" ha permitido visibilizar los fecundos primeros ańos de la década de 1940 en la escritura mistraliana, como se manifiesta en la asiduidad de las publicaciones entre $1940 \mathrm{y}$ 1943 en La Nación, simultáneas a publicaciones y trabajos "de taller" de la escritora durante esta época. Se ha indagado en el epistolario de la poeta con Eduardo Mallea, Martha Salotti, y en forma secundaria, con Victoria Ocampo, para conocer su relación con La Nación. De estos materiales destaca la relevancia de Martha Salotti para la gestión editorial de las obras de Mistral en Argentina, la producción de "recados" o ensayos por parte de Mistral para visibilizar el trabajo de sus amigos en el mundo cultural y la amistad con Eduardo Mallea, trastocada por malentendidos que provocaron un quiebre momentáneo con el medio argentino. Las misivas evidencian una relación compleja entre el mundo editorial y Mistral, en especial, por los intermediarios, la distancia geográfica y la consiguiente lentitud de la correspondencia, en especial, en esta época de guerra. Queda de relieve además, las limitaciones que el cargo de cónsul le imponía a Mistral, por lo que no podía expresar con libertad sus opiniones sobre política.

El poema analizado proviene del afán americanista de Mistral, en concordancia con el plan ideológico de Aguirre Cerda, en cuanto a exaltar a Bernardo O'Higgins como paradigma de la juventud chilena. La perspectiva del prócer que la poeta articula gracias a sus lecturas es la de un hombre íntegro, valiente, con un apego hacia la madre por su condición de hijo natural.

Debido a que los manuscritos conservados no poseen data de producción es imposible saber si la carta de Aguirre Cerda (1940) es el estímulo para escribir "Marcha nocturna", sin embargo, la fecha de edición del poema (15-11-1942), la carta de Amunátegui con datos sobre O'Higgins (08-09-1942) y el fallecimiento del Presidente (1941) nos inducen a manifestar al menos la cercanía entre estos hechos, además de entender la consonancia ideológica entre el pensamiento de Aguirre Cerda y Mistral. Teniendo en cuenta este aspecto, cobra especial significado que la edición del poema se haga en Argentina, como un modo de manifestar la unión de José de San Martín con el libertador chileno, proyectando en esta imagen la deseada unidad latinoamericana.

Los manuscritos nos permiten confirmar que la estructura original del poema era

${ }^{23}$ Son: "en lugar de tos dos se ven" (v.30), "con dunas ni olas de hiel" (v.48), "Carne a-y carne, y puerta a y puerta" (v.57), "Vueltos a noches y a dunas" (v.61). 
el cuarteto octosílabo con rima asonante en los versos pares, los que se construyen en base a binarismos que remiten a los héroes, a la geografía y a la transformación de la materia en espíritu (fantasma). Mistral compone este poema a partir de esta estructura y luego va desarrollando la temática. El texto editado es el menos explícito de las versiones y por tanto el más sugerente; a modo de ejemplo, se percibe un cambio importante en la construcción del espacio en el que se realizará la transformación del cuerpo a espíritu. "Casa de los niños", "niña y sabuesa", "Pampa de milagros", "Pampa desvalida" son formulaciones que persiguen la creación del contexto apropiado para el despojamiento del cuerpo y de su elevación. Mistral opta en la versión de La Nación por el término más simple, Pampa, adjetivado por vieja y sabuesa, términos que en otros textos suyos se asocian a la muerte.

\section{OBRas CITADAS}

Aguirre Cerda, Pedro. 27-05-1940. [Carta a Gabriela Mistral]. Web. 01 de jul. de 2018 <www.bncatalogo.cl/escritor/AE0006335.pdf>

Amunátegui, Gregorio. 8-09-1942. [Carta a Gabriela Mistral]. Web. 01 de jul. de 2018 <www.bncatalogo.cl/escritor/AE0006593.pdf>

Bellemin Nöel, Jean. 2008. Reproducir el manuscrito, presentar los borradores, establecer un ante-texto. Genética textual. Ed. Emilio Pastor Platero. Madrid: Arco/Libros 53-78.

01-09-2011. "Conoce el Legado de Gabriela Mistral en Memoria Chilena". Web. 01 de jul. de 2018 <http://www.memoriachilena.cl/602/w3-article-123325.html>

González Videla, Gabriel. 1938. El Partido Radical y la evolución social de Chile. Santiago: Antares.

Guerrero, Cristian y Ulises Cárcamo. 2013. "Bernardo O’Higgins entre izquierda y derecha. Su figura y legado en Chile: 1970-2008". Cuadernos de historia 39: 113-146.

Mallea, Eduardo. 05-02-1945. [Carta a Gabriela Mistral]. Web. 01 de jul. de 2018 <www. bncatalogo.cl/escritor/AE0008184.pdf>

Mistral, Gabriela. 1939. “La huella”. Sur, IX. 54: 17-19. . 15 -11 - 1942. "Marcha Nocturna". La Nación de Buenos Aires, 2: 1. . Petrópolis, 14-03-1945. [Carta a Eduardo Mallea]. Web. 01 de jul. de $2018<$ www. bncatalogo.cl/escritor/AE0010890.pdf >

. Río de Janeiro, 28-04-1945. [Carta a Eduardo Mallea]. Web. 01 de jul. de 2018 <www.bncatalogo.cl/escritor/AE0010892.pdf > . 10-11-1945. [La cabalgata] en Nuestro Diario, Guatemala. Web. 01 de jul. de 2018 <www.bncatalogo.cl/escritor/AE0016060.pdf>

. 1948. [Cuaderno 33]. Web. 01 de jul. de 2018 <www.bncatalogo.cl/escritor/ AE0013046.pdf>

. Petrópolis, 1948. [Cuaderno 503]. Web. 01 de jul. de $2018<$ <ww.bncatalogo.cl/ escritor/AE0015265.pdf > . 1957. Recados contando a Chile. Santiago: Editorial del Pacífico. 
. 2009a. Almácigo. Santiago: Ediciones Universidad Católica de Chile.

. 2009b. Poesías completas. Santiago: Andrés Bello.

. s.f. [Algo sobre Eduardo Mallea]. Web. 01 de jul. de 2018 <www.bncatalogo.cl/ escritor/AE0013092.pdf>

. s.f. [Carta a Eduardo Mallea]. Web. 01 de jul. de 2018 <www.bncatalogo.cl/escritor/AE0010891.pdf >

. s.f. [Cuaderno 129]. Web. 01 de jul. de 2018 <www.bncatalogo.cl/escritor/ AE0015292.pdf>

. s.f. [Cuadernos] [Poesía, prosa y notas]. Web. 01 de jul. de $2018<$ www.bncatalogo.cl/escritor/AE0015368.pdf>

. s.f. [La cabalgata]. Web. 01 de jul. de 2018 <www.bncatalogo.cl/escritor/ AE0013621.pdf>

. s.f. [La cabalgata]. En [Cuaderno] [Archivador 13]. Web. 01 de jul. de 2018 <www.bncatalogo.cl/escritor/AE0015397.pdf>: 50.

. s.f. [Marcha nocturna]. Web. 01 de jul. de $2018<$ www.bncatalogo.cl/escritor/ AE0015005.pdf>

. s.f. [Recado: O’Higgins]. Web. 01 de jul. de 2018 <www.bncatalogo.cl/escritor/ AE0014213.pdf> .s.f. [Recado sobre una maestra argentina]. Web. 01 de jul. de $2018<$ www.bncatalogo.cl/escritor/ AE0015162.pdf>

Mistral, Gabriela y Ocampo, Victoria. 2007. Esta América nuestra. Correspondencia 19261956. Introducción y notas de Elizabeth Horan y Doris Meyer. Buenos Aires: El cuenco de plata.

Salotti, Martha. 15-05-1941. [Carta a Gabriela Mistral]. Web. 01 de jul. de $2018<$ www. bncatalogo.cl/escritor/ AE0021668.pdf>

. 01-06-1944. [Carta a Gabriela Mistral]. Web. 01 de jul. de $2018<$ www.bncatalogo.cl/escritor/AE0009081.pdf>

. 16-12-1945. [Carta a Gabriela Mistral]. Web. 01 de jul. de 2018 <www.bncatalogo.cl/escritor/ AE0009119.pdf>

Sepúlveda, Alfredo. 2007. Bernardo. Una biografía de Bernardo O'Higgins. Santiago: B Chile, 2007.

Torre, Guillermo de. 11-12-1946. [Carta a Gabriela Mistral]. Web. 01 de jul. de 2018 <www.bncatalogo.cl/escritor/AE0012395.pdf> 
